University of Nebraska - Lincoln

DigitalCommons@University of Nebraska - Lincoln

2009

\title{
Fukuda Stepping Test: Sensitivity and Specificity
}

Julie A. Honaker

University of Nebraska at Lincoln, jhonaker2@unl.edu

Neil T. Shepard

Mayo Clinic, shepard.neil@mayo.edu

Follow this and additional works at: https://digitalcommons.unl.edu/specedfacpub

Part of the Special Education and Teaching Commons, and the Speech Pathology and Audiology Commons

Honaker, Julie A. and Shepard, Neil T., "Fukuda Stepping Test: Sensitivity and Specificity" (2009). Special Education and Communication Disorders Faculty Publications. 20.

https://digitalcommons.unl.edu/specedfacpub/20

This Article is brought to you for free and open access by the Department of Special Education and Communication Disorders at DigitalCommons@University of Nebraska - Lincoln. It has been accepted for inclusion in Special Education and Communication Disorders Faculty Publications by an authorized administrator of DigitalCommons@University of Nebraska - Lincoln. 


\title{
Fukuda Stepping Test: Sensitivity and Specificity
}

DOI: $10.3766 /$ jaaa.20.5.4

Julie A. Honaker*

Thomas E. Boismier $\dagger$

Nathan P. Shepard:

Neil T. Shepard*

\begin{abstract}
Background: A vestibulospinal test known as the Fukuda stepping test (FST) has been suggested to be a measure of asymmetrical labyrinthine function. However, an extensive review of the performance of this test to identify a peripheral vestibular lesion has not been reported.
\end{abstract}

Purpose: The purpose of this study was to evaluate the sensitivity and specificity of the standard FST and a head shaking variation for identification of a peripheral vestibular system lesion.

Research Design: In this retrospective review, we compared performance on the FST with and without a head shaking component to electronystagmography (ENG) caloric irrigation unilateral weakness results.

Study Sample: We studied these factors in 736 chronic dizzy patients.

Results: Receiving operating characteristics (ROC) analysis and area under the curve (AUC) indicated no significant benefit to performance from the head shaking variation compared to the standard FST in identifying labyrinthine weakness as classified by caloric unilateral weakness results.

Conclusions: These findings suggest that the FST with and without head shake component is not a reliable screening tool for peripheral vestibular asymmetry in chronic dizzy patients; however, future research may hold promise for the FST as a tool for patients with acute unilateral disorders.

Key Words: Caloric irrigations, Fukuda stepping test, head shake, unilateral weakness

Abbreviations: $A \cup C=$ area under the curve; FST = Fukuda stepping test; $R O C=$ receiving operating characteristics; UW = unilateral weakness

$\mathrm{T}$ he ability to close one's eyes and step in place without turning depends on normal vestibulospinal and proprioceptive function. In particular, vestibulospinal tests such as stepping tests evaluate motor reactions of the head and neck that are dependent on vestibular sensory input. A variation on the tretversuch test by Unterberger (1938) and the waltzing test by Hirsch (1940) was proposed by Fukuda in 1959 and named the stepping test. The test is suggested to identify the weaker of the labyrinths (not necessarily the side with the lesion) by the direction of the rotation of a patient while walking in place with eyes closed. In the original work by Fukuda, 500 normal subjects were blindfolded and asked to extend both arms and march in place for 50 to 100 steps. The maximum rotation noted was $30^{\circ}$ to either side with 50 steps; a deviation of greater than $30^{\circ}$ about the vertical axis suggested asymmetrical labyrinthine function with the weaker side identified by the direction of rotation.

Peitersen (1964) used a modified version of the Fukuda stepping test (FST) to observe individuals with chronic unilateral inner ear or vestibular nerve damage. Individuals with unilateral dysfunction were noted to rotate to the side of the unilateral deficit. Jordon (1963) examined the reliability of a modified FST on 49 air-crew candidates. Each subject was instructed to perform two 30-step tests at two-hour intervals. A poor correlation between the test performances was noted as the angle of rotation varied for each subject on the two trials. The authors questioned the reliability of predicting imbalance of the labyrinthine system based on the poor reliability scores.

* Division of Audiology, Mayo Clinic, Rochester, MN; †ENT Balance Center, A division of Ear, Nose and Throat Associates, P.C., Fort Wayne, IN; thee and Company, P.C., Missoula, MT

Julie A. Honaker, Ph.D., 200 First Street SW, Rochester, MN 55905; Phone: 507-266-3903; E-mail: honaker.julie@mayo.edu

A portion of this paper was presented as a poster presentation at the $18^{\text {th }}$ Barany Society Meeting, June 6-8, 1994, Uppsala, Sweden. 
Bonanni and Newton (1998) evaluated the testretest reliability of the FST in 30 healthy adults. Subjects performed a 50 -step FST and a 100 -step FST, with a 10-minute rest between each. During these tests, the direction of postural sway and any movement from the starting position was recorded. The results supported the work performed by Fukuda in 1959. It was noted that the subjects in this study demonstrated greater variability in degrees turned and distance moved than Fukuda's original work. Although the 50step test was more reliable than the 100 -step test, the authors concluded that this method should not be used alone as a screening measure for labyrinthine paresis but, rather, with other tests for the vestibular system.

An extensive review of the performance of the FST to identify a peripheral vestibular lesion has not been reported. In the current atmosphere of containment of medical costs, knowledge of the performance of lowcost, low-technical clinical "bedside" tests could be very useful. The purpose of this study was to evaluate the stepping test in a large series of patients with chronic balance disorder using the standard Fukuda stepping test and a head shaking variation. Development of sensitivity and specificity performance figures for identification of a peripheral vestibular system lesion using caloric irrigation results as the "gold standard" was performed.

\section{METHODS}

$\mathrm{I}$ $\mathrm{n}$ this retrospective chart review, 736 chronic balance disorder patients were included in this analysis. Of those patients selected, 702 consecutive chronic balance disorder patients (299 males and 403 females; 15-89 years) were referred to the vestibular testing center at the University of Michigan Medical Center and 34 to the University of Cincinnati (16 males and 18 females; 20 65 years). These patients were extensively evaluated using electronystagmography (ENG) with alternating, bithermal $\left(44^{\circ} \mathrm{C}\right.$ and $\left.30^{\circ} \mathrm{C}\right)$ open loop caloric irrigations and ocular motor testing. Caloric unilateral weakness (UW) was determined by use of Jongkee's formula (Jongkee et al, 1962) Asymmetric slow-component velocity results between ears of $\geq 25 \%$ were indicative of UW. Caloric irrigations are highly reliable in detecting unilateral peripheral vestibular loss (Barber and Stockwell, 1980; Baloh and Honrubia, 1989; Bhansoli and Honrubia, 1999; Brandt and Strupp, 2005) and have served as "gold standard" according to the American Academy of Neurology for presence of peripheral vestibular hypofunction (Fife et al, 2000).

\section{Fukuda Stepping Test}

Prior to caloric irrigation, the patients were evaluated using the Fukuda stepping test with eyes closed and 50 steps in the standard format described by Fukuda (1959). The examiner stood directly behind the patient during the test in a quiet room and instructed the patient to maintain eyes closed following the standard stepping test. The patient's head was then rotated by the examiner for 10-15 sec at a frequency of $3-4 \mathrm{~Hz}$. Patients who could not perform the stepping test or who had incomplete balance function testing were omitted from the study. Of the total 736 subjects, one subject recruited from the University of Michigan did not perform the head shake option, and the 34 recruited from the University of Cincinnati did not undergo the head shake option.

\section{Statistical Analysis}

For the gold standard outcomes of unilateral weakness abnormality (UW\% $\geq 25$ ), logistic regression and ROC (receiving operating characteristics) analysis were performed to assess the usefulness of Fukuda stepping tests for predicting peripheral vestibular paresis. Ideally, the test with the best performance demonstrates a ROC curve furthest from the diagonal to the left (Hanley and McNeil, 1982). Areas under the curve (AUCs) were compared using the method of DeLong et al (1988). The area under an ROC curve summarizes overall diagnostic accuracy: AUCs at approximately 1.0 represent excellent diagnostic accuracy; AUCs closer to 0.5 represent chance performance at detecting those with and those without the condition.

The Fukuda stepping test optimal cut point was identified. The sensitivity, specificity, false negative proportion (1-sensitivity), false positive proportion (1specificity), and likelihood ratio were reported at this cut point. Likelihood ratios measure degree of confidence that a person has a disorder if the test is positive (Sensitivity $\div[100 \%$ - specificity $]$ ). Analyses were performed using JMP (Version 7.0.1, SAS Institute Inc., Cary, NC) and R (Version 2.6.1, R Foundation for Statistical Computing, Vienna, Austria). $\mathrm{P}$ values $<0.05$ were considered statistically significant.

The various testing conditions were grouped according to the criteria used to determine peripheral system involvement. Criteria used for peripheral system involvement and the test conditions were as follows:

Caloric Unilateral Weakness $\geq 25 \%$

1. Stepping test without head shaking-turn toward the weaker labyrinthine side

2. Stepping test without head shaking-independent of turn direction

3. Stepping test following head shaking-turn toward the weaker labyrinthine side

4. Stepping test following head shaking-independent of turn direction 
Fukuda Stepping Test/Honaker et al

Table 1. Results of ROC Analysis of Fukuda Stepping Test Conditions

\begin{tabular}{|c|c|c|c|c|c|c|c|}
\hline Condition & AUC & $\begin{array}{c}\text { Cut } \\
\text { Point* }\end{array}$ & Sensitivity & $\begin{array}{c}\text { False } \\
\text { Negative Rate } \\
\text { (1-sensitivity) }\end{array}$ & Specificity & $\begin{array}{c}\text { False } \\
\text { Positive Rate } \\
\text { (1-specificity) }\end{array}$ & $\begin{array}{c}\text { Likelihood } \\
\text { Ratio }\end{array}$ \\
\hline FST turn toward weaker labyrinth & 0.54 & 5 & 0.5 & 0.5 & 0.61 & 0.39 & 1.29 \\
\hline FST independent of turn direction & 0.54 & 45 & 0.43 & 0.57 & 0.65 & 0.35 & 1.24 \\
\hline FST + HS turn toward weaker labyrinth & 0.53 & 10 & 0.69 & 0.31 & 0.37 & 0.63 & 1.11 \\
\hline FST + HS independent of turn direction & 0.54 & 85 & 0.19 & 0.81 & 0.91 & 0.09 & 2.05 \\
\hline SUM FST + HS independent of turn direction & 0.55 & 50 & 0.57 & 0.43 & 0.54 & 0.46 & 1.22 \\
\hline
\end{tabular}

5. Sum of stepping test results without head shaking plus following head shaking-independent of turn direction

\section{RESULTS}

$\mathrm{T}$ he final sample consisted of 736 participants. The average age range group of the 736 subjects was 40 49 years of age. During the Fukuda stepping test without head shake ( $\mathrm{n}=736), 323(44 \%)$ showed a tendency to rotate to the right, 264 (36\%) showed a tendency to rotate to the left, and 147 (20\%) indicated no turn or zero deviation. For the Fukuda with head shake $(\mathrm{n}=701), 217(31 \%)$ showed a tendency to rotate to the right, $379(54 \%)$ showed a tendency to rotate to the left, and $105(15 \%)$ did not deviate from the starting position.

The ROC curves were constructed to determine if FST with and without head shaking component could discriminate between those patients with and without a significant caloric unilateral weakness. The results of ROC analysis of each Fukuda stepping condition with reference to caloric unilateral weakness $(\geq 25 \%)$ were the standard to determine peripheral system involvement and are summarized in Table 1.

When comparing area under the curve to determine if the Fukuda stepping test with and without head shake can identify the weaker labyrinth, there was no significant difference between tests (comparison of AUC, $p$ value $=.949$ ). Further, no significant benefit to performance was derived from the head shaking variation compared to the standard stepping test independent of turn direction (comparison of AUC, p-value $=0.860$ ). The sum of the angular rotation independent of turn side without head shaking plus the rotation angle following head shaking did not provide an increase in the performance (comparison of AUC, p-value $=0.622$ ).

\section{DISCUSSION}

$\mathrm{T}$ he Fukuda stepping test has been widely used for evaluating labyrinthine function; however, our data do not support conclusions by Fukuda (1959) and Peitersen (1964) that individuals with unilateral vestibular lesions tend to deviate toward the affected ear. The addition of the head shaking variation did not significantly improve performance over the standard test; that is, identification of a different population of patients with peripheral involvement was not observed. Support for this was indicated by comparing the areas under the curve for conditions 2,4 , and $5(\mathrm{p}$ value $=0.622$, no difference).

Some limitations with this study must be underlined. First, as we only included subjects with chronic disorders (symptom complaint for eight weeks or longer) our results cannot be extrapolated to all patients with peripheral vestibular lesions. Second, our study did not define our sample in terms of compensations (i.e., compensated vs. uncompensated peripheral lesion resulting in caloric weakness $\geq 25 \%$ ). It should be noted that our study population consisted of partially compensated chronic balance disorder patients; however, data on spontaneous and positional nystagmus was not collected for analysis in our study. While it would be anticipated that the greater the lack of physiologic compensation, the more likely a positive result on a test of vestibulo-spinal function like the stepping test, our data analysis was not designed to evaluate this hypothesis. Third, other research studies (Peitersen, 1963, 1964; Hickey et al, 1990) involving patients with vestibular deficits have shown an increased angle of deviation as compared to age-matched controls with no complaints of dizziness or problems with balance. In our study, a control group was not included.

From the results of this study, the FST did not provide significant findings that would support the use of this test as a reliable screening tool for peripheral vestibular asymmetry in chronically dizzy patients. Our results agree with previous reports by Bonanni and Newton (1998) stating that the FST should not be used alone as a screening method. However, Peitersen (1967) and Bonanni and Newton (1998) have suggested the use of the FST in combination with other clinical tests (e.g., electronystagmography, rotational chair, head thrust, and head-shaking tests) in the assessment of vestibular pathologies. We suggest its use 
solely as part of a parallel strict (i.e., all additional clinical tests are positive to suggest peripheral vestibular lesion) test protocol.

Normal FST results in the presence of caloric unilateral weakness $\geq 25 \%$ may not rule out the possibility of a unilateral peripheral vestibular pathology but may simply imply adequate vestibulo-spinal compensation (Hickey et al, 1990). While the FST was not an accurate predictor of unilateral vestibular dysfunction in our cohort of patients with chronic balance disorders, it may serve as a tool for patients with acute unilateral labyrinthine disorders. Further studies regarding the diagnostic usefulness of the FST in patients with acute (symptom complaints for less than two weeks) vestibular dysfunction are warranted.

\section{REFERENCES}

Baloh RW, Honrubia V. (1989) Clinical Neurophysiology of the Vestibular System. Philadelphia: FA Davis.

Barber HO, Stockwell CW. (1980) Electronystagmography. St. Louis: CV Mosby.

Bhansoli SA, Honrubia V. (1999) Current status of electronystagmography testing. Otolaryngol Head Neck Surg 120:419-426.

Bonanni M, Newton R. (1998) Test-retest reliability of the Fukuda stepping test. Physiother Res Int 3(1):58-68.

Brandt T, Strupp M. (2005) General vestibular testing. Clin Neurophysiol 116:406-426.

DeLong ER, DeLong DM, Clarke-Pearson DL. (1988) Comparing the areas under two or more correlated receiver operating characteristic curves: a nonparametric approach. Biometrics 44: 837-845.
Fife TD, Tusa RJ, Furman JM, Zee DS, Frohman E, Baloh RW, Hain T, Goebel J, Demer J, Eviatar L. (2000) Assessment: vestibular testing techniques in adults and children: Report of the Therapeutics and Technology Subcommittee of the American Academy of Neurology. Neurology 55:1431-1441.

Fukuda T. (1959) The stepping test. Acta Otolaryngol (Stockholm) 50:95-108.

Hanley JA, McNeil BJ. (1982) The meaning and use of the area under a receiver operating characteristic (ROC) curve. Radiology 143(1):29-36.

Hickey SA, Ford GR, Buckley JG, Fitzgerald O’Connor AF. (1990) Unterberger stepping test: a useful indicator of peripheral vestibular dysfunction? J Laryngol Otol 104(8):599-602.

Hirsch C. (1940) A new labyrinthine reaction: the waltzing test. Ann Otol Rhinol Laryngol 49:232-238.

Jongkee LB, Maas J, Philipszoon A. (1962) Clinical nystagmography: a detailed study of electronystagmography in 341 patients with vertigo. Pract Otorhinolaryngol (Basel) 24:65-93.

Jordan P. (1963) Fukuda's stepping test: a preliminary report on reliability. Arch Otolaryngol 77:243-245.

Peitersen E. (1963) Vestibulospinal reflexes: acute disturbances of vestibular function after operations on the stapes, especially as evaluated by the stepping test. Acta Otolaryngol 78:642-684.

Peitersen E. (1964) Vestibulospinal reflexes: alterations in the stepping test in various disorders of the inner ear and vestibular nerve. Acta Otolaryngol 79:481-486.

Peitersen E. (1967) Vestibulospinal reflexes. X. Theoretical and clinical aspects of the stepping test. Arch Otolaryngol 85:192198.

Unterberger S. (1938) Neue objective registrierbare vestibulariskorper-drehreaktion, erhalten durch treten auf der stelle. Der "tretversuch." Arch Ohren-usw Heilk 145:478. 